\title{
A aprendizaxe-servizo en perspectiva. John Dewey como referente histórico
}

\author{
Service-Learning in Perspective. \\ John Dewey as a Historical Reference
}

\author{
Alexandre SOTELINO LOSADA \\ Grupo de Investigación Esculca \\ Universidade de Santiago de Compostela
}

RESUMO: A metodoloxía do service-learning é relativamente nova como tal, xa que o seu nacemento data de principios do século $X X$, aínda que non recibiu o seu nome definitivo ata tempos relativamente recentes. $O$ pioneiro para a maioría de autores é o coñecido filósofo e pedagogo John Dewey, a que nos referiremos nun apartado específico, dada a súa contribución á filosofía conformadora desta metodoloxía. Interesaranos examinar a medida en que a súa obra pedagóxica aparece reflectida no que na actualidade chaman, e chamamos, aprendizaxe-servizo.

$\mathrm{O}$ auténtico pulo desta metodoloxía prodúcese no último terzo do século $\mathrm{XX}$, con especial relevancia nos Estados Unidos. A Europa non chegará ata os anos noventa da pasada centuria, e pode dicirse que a súa andaina en España apenas é perceptible ata a inauguración do novo século XXI.

PALABRAS CHAVE: Aprendizaxe-servizo, pedagoxía, educación cívica, John Dewey.

ABSTRACT: Service-learning methodology is a relatively new concept, since it was born at the beginning of the 20th Century, yet its name was not finally coined until relatively recent times. The pioneer for most authors is the well-known philosopher and pedagogue John Dewey, to whom we may refer in a specific section, given his contribution to the informant philosophy of this methodology. We are interested in examining to what extent his pedagogic work is reflected in what we know today as service-learning.

The real boom occurred in the last third of the century, especially in the United States. Yet it did not reach Europe until the 90's of the last century, and it might be said, its existence in Spain is barely noticeable until the inauguration of the new century.

KEYWORDS: Service-learning, Pedagogy, Civic Education, John Dewey. 
A historia da metodoloxía de pedagoxía experiencial denominada aprendizaxe-servizo $(A p S)^{1}$ remóntase tan só un século atrás, cando algúns científicos sociais, entre os que sobresaen John Dewey e William James, comezaban a traballar coa aprendizaxe a través da experiencia e a interrelación co medio circundante ${ }^{2}$.

Neste proceso de construción e consolidación metodolóxica podemos contar por centos as definicións dadas do constructo aprendizaxe-servizo. Cada unha intenta achegar unha nova visión ou concepción do que se entende por tal tópico. En primeiro termo o que nós faremos será resaltar aquelas que nos parecen máis relevantes, e aquelas con que estamos máis de acordo pola súa concreción; e a partir de aí acentuaremos os aspectos comúns, para extraer así o que se entende por ApS nun nivel xeral, á marxe de particularidades. Polo tanto, non nos marcamos como obxectivo poñer unha nova pedra na montaña rochosa das definicións, senón que pretendemos extraer a esencia común destas para poder entender esta metodoloxía.

Comezaremos presentando algunhas das definicións básicas que se utilizan no contexto anglosaxón, por ser este onde o service-learning se atopa máis desenvolvido. A primeira será a que se recolle na Complete Guide to Service Learning de Cathryn Berge Kaye, unha guía básica que intenta introducir as persoas na metodoloxía. Dise alí que a aprendizaxe-servizo pode ser definida como "un método de ensino onde se afonda na aprendizaxe a través do servizo a outros, nun proceso estruturado que fomenta a reflexión sobre a experiencia e onde se demostran as habilidades e coñecementos adquiridos"3.

Pola súa vez, dous dos principais autores deste campo, como son Furco e Billig, definen o service-learning como un enfoque de ensino-aprendizaxe que implica que os estudantes leven a cabo un servizo comunitario como medio para o logro das metas académicas ${ }^{4}$. Estes mesmos autores teñen editado un libro de referencia cuxo título é revelador da importancia que lle outorgan a este enfoque educativo, Service-Learning: The Essence of the Pedagogy. Outros dous autores clave no contexto anglosaxón, Eyler e Giles, concrétano dicindo que a aprendizaxe-servizo debe incluír un equilibrio entre o servizo á comunidade e a aprendizaxe académica, e o guión na denominación simboliza o papel central que ten a reflexión neste proces $0^{5}$. Faise outra volta incidencia no equilibrio que debe existir entre 0 "servizo" e a "aprendizaxe académica", así como na conexión entre ambas as dimensións, que non é outra que a reflexión profunda sobre o acontecido.

\footnotetext{
${ }^{1}$ En diante empregaremos tanto a denominación completa, aprendizaxe-servizo ou service-learning, como a abreviatura ApS.

${ }^{2}$ Quero facer constar o meu agradecemento explícito aos profesores X. M. Malheiro e Antón Costa polas interesantes suxestións que achegaron na revisión deste artigo.

${ }^{3}$ C .B. Kaye, The Complete Guide to Service Learning. Proven, Practical Ways to Engage Students in Civic Responsibility, Academic Curriculum \& Social Action (Minneapolis: Free Spirit Publishing Inc., 2004), 7.

${ }^{4}$ S. Billig e A. Furco, Service-Learning. The Essence of the Pedagogy (Charlotte: Information Age Publishing, 2002), 7.

${ }^{5}$ J. Eyler e D. E. Giles, Where's the Learning in Service-Learning? (California: Jossey-Bass Publishers, 1999), 4.
} 
No contexto latino, unha das principais tratadistas é María Nieves Tapia, que desde Bos Aires (Arxentina) leva anos traballando en materia de "aprendizaxe e servizo solidario", que é como o denomina, a respecto de que se destacan os seguintes trazos definitorios ${ }^{6}$ :

- Trátase dun servizo solidario desenvolvido polos estudantes,

- destinado a atender, de forma acoutada e eficaz, necesidades reais e efectivamente sentidas dunha comunidade,

- e planificado institucionalmente de forma integrada co currículo, en función da aprendizaxe dos estudantes.

Vexamos agora a definición máis utilizada no contexto hispano. É a elaborada por Puig et al. ${ }^{7}$ como "una propuesta educativa que combina procesos de aprendizaje y de servicio a la comunidad en un solo proyecto bien articulado en el que los participantes se forman al trabajar sobre necesidades reales del entorno con el objetivo de mejorarlo". Non é outra a definición que se usa no Centre Promotor de Aprenentatge Servei de Cataluña e na Fundación Zerbikas de Euskadi, que son, hoxe, os dous núcleos máis consistentes -organizativamente falando- de fomento desta metodoloxía no Estado español.

No seu último libro sobre a cuestión, Josep María Puig8 define a ApS como "una metodología que combina en una sola actividad el aprendizaje de contenidos, competencias y valores con la realización de tareas de servicio a la comunidad. En el aprendizaje-servicio el conocimiento se utiliza para mejorar algo de la comunidad y el servicio se convierte en una experiencia de aprendizaje que proporciona conocimientos y valores". Cómpre salientar o feito de que se cambie a expresión "proposta pedagóxica" por "metodoloxía", o que modifica substancialmente a concepción da aprendizaxe-servizo.

Referíndonos á Comunidade galega, son os profesores Miguel A. Santos Rego e Mar Lorenzo Moledo os que máis se fixeron eco desta metodoloxía. Nunha das súas últimas publicacións fan referencia á aprendizaxe-servizo como aquelas "actividades escolares con clara proxección social. $\mathrm{O}$ obxectivo é que os alumnos adquiran os contidos académicos programados dende o currículo das diferentes materias, realizando un servizo de utilidade social no medio"s.

Na mesma obra, estes profesores observan que en Galicia a eficacia desta metodoloxía podería verse reforzada pola gran cantidade de estímulos concentrados e próximos ligados ao territorio e á cultura, elementos intrínsecos dunha realidade histórica en que unha proposta destas características supón oportunidades para o desenvolvemento da aprendizaxe e da comunidade.

\footnotetext{
${ }^{6}$ M. N. Tapia, Aprendizaje y servicio solidario (Madrid: CCS-ICCE, 2004), 20.

${ }^{7}$ J. M. Puig et al., Aprendizaje servicio. Educar para la ciudadanía (Barcelona: Octaedro, 2007), 20.

${ }^{8} \mathrm{~J}$. M. Puig et al., Aprendizaje servicio (ApS). Educación y compromiso cívico (Barcelona: Graó, 2009), 9.

${ }^{9}$ M. Lorenzo e M. A. Santos Rego, Educación para a cidadanía e os profesores. Visión e desafío (Vigo: Edicións Xerais, 2009), 81.
} 
Todos os autores e institucións parecen incidir nos mesmos aspectos, aínda que na maioría das ocasións con pequenos matices diferenciais entre unhas e outras definicións. O que comparten todas elas son certas características que de maneira combinada dan lugar aos proxectos de aprendizaxe-servizo, e que son estas: aprendizaxe sistematizada, servizo real e intencional, proxecto con intencionalidade pedagóxica, participación activa e reflexión.

Nalgunha ocasión escoitamos dicir a Roser Batlle ${ }^{10}$ que a aprendizaxe-servizo non é un invento, senón un descubrimento. Isto é, un paso máis alá das prácticas coñecidas por todos (voluntariado, traballos de campo, practicum...), que influenciadas polos cambios sociais foron esixindo novas demandas e reformulacións. Para poder entender de mellor xeito esta evolución propuxémonos facer unha revisión histórica da configuración da metodoloxía, comezando polo que podemos entender como o seu precursor, o pedagogo John Dewey.

\section{Os primeiros pasos do service-learning. A achega de John Dewey}

É ben sabido que o estadounidense John Dewey foi un dos grandes filósofos e pedagogos do noso tempo. Exerceu unha moi notable influencia sobre a teoría e a praxe científica no actual pensamento pedagóxico. É definido como pragmatista, posto que as súas premisas apuntan na dirección dunha educación baseada na experiencia da interrelación co medio, de tal maneira que, do seu punto de vista, experiencia e pensamento son, en certo modo, a mesma cousa, desde o momento en que a primeira esixe un alto grao de reflexión ${ }^{11}$.

Segundo González ${ }^{12}$, a confrontación que cada persoa ten coas súas múltiplas experiencias vitais acontece procesualmente, se estimamos a obra de Dewey a través de cinco estadios:

1. Perplexidade

2. Anticipación por conxectura

\section{Revisión coidadosa}

4. Elaboración conseguinte da hipótese

5. Plan de acción

\footnotetext{
${ }^{10}$ Educaweb, "El aprendizaje-servicio une el éxito escolar con el compromiso social de niños, niñas y jóvenes, de manera que éstos tengan la oportunidad, por lo menos una vez en su proceso educativo, de actuar como ciudadanos. Entrevista a Roser Batlle. Licenciada en Pedagogía por la Universitat de Barcelona y miembro de la Asociación Ashoka Emprendedores Sociales, para desarrollar el proyecto de difusión del aprendizaje-servicio en España", Educaweb.com (15/11/2010): dispoñible en http://www.educaweb.com/noticia/2010/11/15/entrevistaroser-batlle-aprendizaje-servicio-4469.

${ }^{11}$ R. Bernstein, Filosofía y democracia: John Dewey (Barcelona: Herder Editorial, 2010).

${ }^{12} \mathrm{~J}$. González, "John Dewey y la pedagogía progresista", en El legado pedagógico del siglo XX para la escuela del siglo XXI, coord. J. Trilla (Barcelona: Graó, 2001), 25.
} 
Dewey, desde a súa formación inicialmente darwiniana, tomaba como referencia a teoría da evolución da mente, nunha hipótese xenética e funcional da evolución psicolóxica ${ }^{13}$. Deste xeito, entende que "el pensamiento constituye para todos un instrumento destinado a resolver los problemas de la experiencia y el conocimiento es la acumulación de sabiduría que genera la resolución de problemas"14. O propio Dewey ${ }^{15}$ comenta que "la experiencia como ensayo supone cambio, pero el cambio es una transición sin sentido a menos que la experiencia esté conscientemente conexionada con la ola de retorno de las consecuencias que fluyen de ella. Cuando de una actividad se derivan consecuencias, cuando el cambio introducido por la acción se refleja en un cambio producido por nosotros, entonces el mero fluir está cargado de sentido. Aprendemos algo". Destas palabras extráese que o simple feito de ter que producir cambios e buscar a vía para realizalos, supón un profundo exercicio de reflexión, o cal ten un gran valor educativo, ao ter que desenvolver un notorio poder de capacidade crítica e reflexiva ${ }^{16}$.

O seu modelo pedagóxico é o chamado Learning by Doing (Dewey 1918 [1915]) ${ }^{17}$, que se fundamenta na idea de que o coñecemento certo é o que se deriva da experiencia ou da utilidade, posto que as únicas aprendizaxes relevantes son as que resultan útiles. Así, a unión de medios e fins, segundo a adquisición de coñecementos, debería subordinarse na escola á resolución de problemas na vida real, mediante un proceso metodolóxicodedutivo que Dewey desenvolve.

No seu libro Democracia y educación, Dewey ${ }^{18}$ afirma que "el ambiente social consiste en todas las actividades de todos los seres semejantes que intervienen en el desarrollo de las actividades de todos sus miembros. Aquel es verdaderamente educador en sus efectos en la medida en que un individuo comparte o participa en alguna actividad conjunta. Al realizar su participación en la actividad asociada, el individuo se apropia del propósito que la motiva, se familiariza con sus métodos y materias, adquiere la destreza necesaria y se satura de su espíritu emocional". Así, as persoas conseguen realizarse empregando os seus talentos peculiares co fin de contribuíren ao benestar da súa comunidade, "razón por la cual la función principal de la educación en toda sociedad democrática es ayudar a los niños a desarrollar un carácter - conjunto de hábitos y virtudes que les permita realizarse plenamente de esta forma-"19. Deixaba claro, polo tanto, que a experiencia é a base para a adquisición do coñecemento, o cal enlaza coa cita clásica de Confucio: "Contáronmo e esquecino; vino e entendino; fíxeno e aprendino".

\footnotetext{
${ }^{13}$ A. Costa, A construción do coñecemento pedagóxico. Antecedentes e desenvolvementos no século XX (Santiago de Compostela: ICE-USC, 2009).

${ }^{14}$ R. B. Westbrook, "John Dewey (1859-1952)", Perspectivas: revista trimestral de educación comparada, 23 (1993): 289-305.

${ }^{15}$ J. Dewey, Democracia y educación, traducción de Lorenzo Luzuriaga (Madrid: Morata, 1995 [1916]), 124.

${ }^{16} \mathrm{~J}$. Dewey, Cómo pensamos. La relación entre pensamiento reflexivo y proceso educativo (Barcelona: Paidós, 2007 [1931]).

${ }^{17}$ J. Dewey e E. Dewey, Las escuelas del mañana (Madrid: Librería de los sucesores de Hernando, 1918 [1915]).

${ }^{18}$ Dewey, Democracia y educación, 30-31.

${ }^{19}$ Westbrook, "John Dewey (1859-1952)", 293.
} 
A maioría de autores coinciden en dicir que John Dewey é o gran precursor do servicelearning. As premisas que este científico defendía ían en tal liña de intervención educativa. No modelo do learning by doing, que anteriormente describiamos, poderemos encontrar moitas coincidencias coa metodoloxía da ApS, comezando polo obxectivo básico na mesma base de partida, que é a optimización da aprendizaxe do alumnado mediante a realización dun servizo á comunidade, por outra parte, tamén tradicionalmente elaboradas desde a perspectivas natorpianas ${ }^{20}$, tan consolidadas polos estudosos alemáns da pedagoxía social ${ }^{21}$. Giles e Eyler ${ }^{22}$ suxerían no seu traballo de 1994 nove áreas para que servisen de base ao desenvolvemento da metodoloxía do service-learning. Son as que a continuación se expoñen:

1) A continuidade da experiencia

2) O principio de interacción

3) Investigación/indagación

4) Actividade reflexiva

5) Proxecto verdadeiramente educativo

6) Coñecemento concreto e abstracto

7) A gran comunidade

8) Cidadanía

9) Democracia

Dous anos máis tarde, Saltmarch ${ }^{23}$ volve facer unha análise da contribución da obra de Dewey á pedagoxía do service-learning, e chega a resumir en cinco as áreas que marcan a influencia de tan insigne intelectual na metodoloxía que conforma o eixe do noso traballo. Este é o xeito en que as presenta:

1) Vinculación de educación con experiencia

2) Comunidade democrática

3) Servizo socialmonicamonterolim@gmail.com

4) Investigación/indagación reflexiva

5) Educación para o cambio social

Como se pode observar, nas dúas investigacións existen claros puntos de coincidencia, aínda que no caso de Saltmarch o que se pretende é agrupar algunhas das categorías anteriormente expostas por Giles e Eyler. Poderiamos entrar a valorar cal das dúas conceptualizacións é máis precisa, pero a intención non é esa, senón ver como realmente podemos encontrar moitos aspectos comúns co que hoxe en día entendemos como service-learning e o que Dewey denominaba learning by doing.

\footnotetext{
${ }^{20}$ P. Natorp, Curso de pedagogía social (México: Porrúa, 1905). ${ }^{21}$ S. Horst e K. Zenke, Diccionario Akal de pedagogía (Madrid: Akal, 2001).

${ }_{22} \mathrm{~J}$. Giles e J. Eyler, "The Theoretical Roots of Service-Learning in John Dewey: Toward a Theory of ServiceLearning", Michigan Journal of Community Service Learning, 1 (1994): 77-85.

${ }^{23} \mathrm{~J}$. Saltmarch, "Education for Critical Citizenship: John Dewey's Contribution to the Pedagogy of Community Service Learning", Michigan Journal of Community Service Learning, 3 (1996): 13-21.
} 
Para Dewey a democracia é a forma de vida que precisan as persoas para gozaren da mellor, máis rica e máis plena experiencia posible ${ }^{24}$. Velaquí o principal ideal deweyano. Neste sentido, a educación deberá orientarse a formar as novas xeracións para que sexan máis críticas e reflexivas no tocante ás realidades que as rodean, pois sen unha cidadanía que estea realmente instruída non hai réxime democrático capaz de subsistir ${ }^{25}$. Este ideal conecta directamente coas premisas que persegue a aprendizaxe-servizo en tanto que metodoloxía capaz de formar dun xeito diferente a partir da potenciación de valores e capacidades propiamente democráticas como a empatía, a negociación, o liderado, o traballo en grupo ou a solidariedade, de maneira que o ben común sexa o maior dos beneficios dun proceso de ensino-aprendizaxe.

En definitiva, e tendo en conta a literatura científica, podemos concluír que efectivamente John Dewey é, senón o primeiro autor vinculado á ApS, si o máis influente na súa construción teórica, observado isto desde o contexto hispano. As súas premisas sintonizan cun xeito de entender a educación que nos leva a albiscar sociedades máis democráticas, abertas e reflexivas, algo que só se poderá conseguir se os procesos formativos van mudando atendendo máis á pedagoxía e menos á economía.

\section{O desenvolvemento metodolóxico. Os Estados Unidos de América como referencia}

Os Estados Unidos de América son o lugar do planeta onde máis se desenvolveu a metodoloxía do service-learning e, xa que logo, onde máis literatura encontramos sobre o tópico. Sendo así, non sería conveniente deixar de facer referencia á evolución da ApS neste país, pois alí naceu, alí se foi construíndo e desde alí se estendeu a un bo número de países ${ }^{26}$.

É no país americano onde se considera que se utilizou por primeira vez o termo service-learning, en 1967, cando William Ramsay, Robert Sigmon ${ }^{27}$ e Michael Hart o empregaron para describiren un proxecto de desenvolvemento local levado adiante por estudantes e docentes do consorcio OAK Ridge Associated Universities en Tennessee ${ }^{28}$, aínda que non se consolidou a expresión ata a primeira ${ }^{29}$ Service Learning Conference, que tivo lugar en Atlanta en $1969^{30}$.

Son diferentes os apuntamentos que podemos facer sobre a orixe e as primeiras prácticas do service-learning, existindo múltiples ideas no seu círculo de influencia. Neste sentido, o que faremos a seguir será utilizar diferentes documentos e traballos da literatura

\footnotetext{
${ }^{24}$ Dewey, Democracia y educación.

${ }^{25}$ J. Dewey, Democracia y escuela (Madrid: Editorial Popular, 2009).

${ }^{26} \mathrm{M}$. A. Santos Rego, "¿Para cuándo las universidades en la agenda de una democracia fuerte? Educación, aprendizaje y compromiso cívico en Norteamérica", Revista de Educación, 361 (2013): 565-590.

${ }^{27}$ R. Sigmon, The Journey to Service-Learning (Washington D. C.: Council of Independent Colleages, 1996).

${ }^{28}$ E. Ochoa, "Aprendizaje-servicio en América Latina: apuntes sobre pasado y presente", Revista Tzhoecoen, edición especial dedicada al aprendizaje-servicio, 5 (2010): 108-125.

${ }^{29}$ D. J. Eberly, National Service: A Promise to Keep. (Nova York: Alden Books, 1988).

${ }^{30}$ P. Titlebaum et al., Annotated History of Service-Learning: 1862-2002 (Dayton: University of Dayton, 2004).
} 
existente ${ }^{31}$ para tratar de ofrecer unha liña temporal ${ }^{32}$ en que sexa posible apreciar a súa evolución ${ }^{33}$, xusto desde principios do século XX ${ }^{34}$.

Na primeira metade do século XX producíronse diferentes sucesos que de maneira conxunta foron construíndo os piares para que posteriormente a aprendizaxe-servizo puidese definirse como tal no contexto estadounidense. Mesmo podemos chegar a afirmar que neste período William James e John Dewey desenvolveron os fundamentos pedagóxicos da metodoloxía.

Deste xeito, foron múltiplas as experiencias de servizo comunitario que xurdiron, como a do Civilian Conservation Corps (CCC), creado por Franklin D. Roosevelt, onde millóns de mozos estiveron meses axudando a restaurar os parques do país, revitalizando ao mesmo tempo a economía; ou a do GI Bill, que unía servizo e educación, brindando oportunidades educativas aos estadounidenses a cambio de servizos ao seu país.

No ano 1961 o presidente John F. Kennedy crea o Corpo de Paz, con que se autoriza a lexislación aprobada polo Congreso o 22 de setembro 1961. Tres anos despois, como parte do seu programa de guerra contra a pobreza, o presidente Lyndon B. Johnson crea o programa de Voluntarios ao servizo de América (VISTA), o Corpo Nacional de Mestres, o Corpo de Emprego e o Ano da Universidade de Acción. Búscase proporcionar así oportunidades para os estadounidenses axudaren a miles de comunidades de baixos ingresos.

A partir deste momento os acontecementos sucédense de maneira máis continuada e mesmo se pode dicir que apresurada, consolidando o service-learning nestas latitudes.

1966-1967. O termo service-learning úsase para describir un proxecto financiado pola TVA (Tennessee Valley Authority) no leste de Tennessee co consorcio Oak Ridge Associated Universities. $O$ dito proxecto vinculaba os estudantes e os profesores con organizacións da área de desenvolvemento.

1968. Ten lugar en Washington D. C. a National Service Secretariat Conference.

1969. Ten lugar en Atlanta a Service Learning Conference, cuxos patrocinadores foron a Southern Regional Education Board o U.S. Deparment of Health, Education and Welfare, a cidade de Atlanta, os Atlanta Urban Corps, o Corpo de Paz e o programa VISTA.

1971. Conferencia na Casa Branca sobre o informe completo da xuventude nas convocatorias da vinculación de servizo e aprendizaxe. Ademais, créanse o National Center for Public Service Internship e a Society for Field Experience Education (que se fusionaron no ano 1978 para converterse na National Society for Internships and Experiential Education). Establécese o National Student Volunter Program (que deu lugar á aparición do Centro

\footnotetext{
${ }^{31}$ P.Titlebaum, A History of Service Learning. (www.servicelearning.org, 2002).

${ }^{32}$ Learn and Serve America, Service-learning History Timeline. (www.learnandserve.gov, 2008).

${ }^{33}$ National Service-Learning Clearinghouse, History of Service-Learning in Higher Education. (www. servicelearning.org, 2008).

${ }^{34}$ National Service-Learning Partenship, Service-Learning. (www.service-learningpartnership.org, 2008).
} 
Nacional de Aprendizaxe-Servizo en 1979). Xorde Synergist, unha publicación sobre a promoción da vinculación entre servizo e aprendizaxe.

1978. O Young Adult Conservation Corps Program crea pequenos grupos nos estados con 22500 participantes de idades entre os 16 e os 23 anos.

1979. Synergist publica os tres principios do service-learning.

1981. Establécese o Centro Nacional de Aprendizaxe-Servizo para adolescentes temperáns.

1982. Fúndase o National Youth Leadership Council para axudar a preparar os futuros líderes.

1984-1985. Os esforzos nacionais poñen en marcha iniciativas como a Campus Outreach Opportunity League (1984) e Campus Compact (1985), que axudan a activar programas de servizo no ensino superior. A National Association of Service and Conservation Corps (1985) promove a unión de mozos nos estados e cidades; e Youth Service America (1985) ofrece a moitos mozos a oportunidade de exerceren distintas actividades de servizo.

1989. Os dez Wingspread Principles of Good Practice for Combining Service and Learning foron desenvolvidos en colaboración por máis de setenta organizacións.

Créanse a Office of National Service in the White House e a Points of Light Foundation para fomentar o voluntariado.

1990. O Congreso Nacional aproba, e o presidente Bush ratifícaa, a National and Community Service Act. A lexislación autoriza a outorgar subvencións ás escolas para apoiar a aprendizaxe-servizo, alén de axudas a programas de servizo para a xuventude, sen fins de lucro, en institutos e universidades.

1992. A Xunta de Educación do Estado de Maryland adopta os requisitos para establecer como obrigatoria unha experiencia de service-learning, co fin de obter o título de graduado/a. Tales requisitos fanse efectivos a partir de 1993, o cal afectaba aos estudantes graduados en 1997 e con posterioridade.

1993. A Asociación de Supervisión e Desenvolvemento Curricular (ASDC) referenda a importancia de vincular a aprendizaxe co servizo. O presidente Bill Clinton asina a National and Community Service Trust Act de 1993, pola cal se crea o AmeriCorps e a Corporación Nacional para o Servizo. A lexislación une os Sénior Corps, AmeriCorps VISTA e Learn and Serve nunha axencia federal independente.

1994. O Congreso aproba a King Holiday and Service Act, e encarga á Corporación Nacional para o Servizo a organización da iniciativa do Día de Martin Luther King como unha xornada de servizo. Créase o Stanford Service-Learning Institute. A Fundación Ford/ United Negro Service College funda o Community Service Partnership Project, en que se implican unha decena de universidades. 
1995. Créase a Network de aprendizaxe e servizo en Internet, a través do Centro de Estudos para a Paz da Universidade de Colorado.

2001. Ten lugar a I Conferencia Internacional sobre Investigación en Aprendizaxe e Servizo e a Participación Cívica do Estudante.

2002. Póñense en marcha o Corpo de Liberdade dos EUA, un consello de coordinación e unha oficina da Casa Branca para axudar a difundir a chamada ao servizo feita por George W. Bush a todos os estadounidenses.

2003. Nace o President's Council on Service and Civic Participation, para encontrar e valorar diferentes formas de recoñecemento aos voluntarios que serven aos Estados Unidos.

2007. Xorde en Tulane, Nova Orleáns, a International Association for Research on Service-Learning and Community Engagement (IARSLCE), a partir da K-H Service Learning Research Conference. Esta asociación ten por finalidade promover a investigación e o debate sobre a aprendizaxe-servizo e o compromiso coa comunidade. Entre outras actividades, organiza anualmente 0 encontro antes nomeado.

2009. Barack Obama asinou a Edward M. Kennedy Serve America Act en Washington D. C., co que reautorizaba á Corporation for National and Community Service a expandir e administrar este tipo de programas en toda a nación.

Cabe sinalarmos que o servizo non vai ser entendido de igual maneira en todos os momentos, en certa medida baixo a influencia das varias correntes do poder político. Algo que de partida debe ser un acto propiamente cívico con finalidade solidaria, pódese converter, utilizado de maneira perniciosa, nun instrumento político que en situacións extremas pode redundar nunha precarización do mercado laboral. Ante isto, desde as formulacións da socioloxía educativa crítica, reclámase a revalorización educativa da aprendizaxe-servizo ${ }^{35}$, no sentido máis amplo da palabra, para axudar así a que o traballo recupere "as súas tradicións parcialmente perdidas" ${ }^{36}$.

\section{A aprendizaxe-servizo e a súa expansión en América Latina: de onte a hoxe}

Tendo os Estados Unidos de América como referencia, a ApS comezou a estenderse a diferentes puntos do globo hai dúas décadas, cunha especial repercusión en América Latina, onde podemos atopar bos exemplos de aprendizaxe-servizo en países como México, Arxentina, Uruguai e outros lugares de América Central, que mesmo gozan de apoio gobernamental e social.

En América existe, pois, unha tradición consolidada da ApS tanto nas escolas como nas universidades. Podería entenderse como unha resposta cidadá á profunda crise que

${ }^{35} \mathrm{H}$. Giroux, Los profesores como intelectuales. Hacia una pedagogía crítica del aprendizaje (Barcelona: Paidós, 1990).

${ }^{36}$ M. W. Apple, Educación y poder (Barcelona: Paidós, 1987). 
sufriron nos pasados anos oitenta e noventa gran parte dos países latinoamericanos. Deste xeito, foron moitos os proxectos de servizo á comunidade que empezaron a implantarse desde diferentes institucións. A aprendizaxe-servizo foi un paso que axudaba a dar aínda máis sentido a esas prácticas solidarias ${ }^{37}$.

Nalgúns países o éxito desta metodoloxía foi tal que mesmo se institucionalizou. É o caso de Arxentina, onde o Ministerio de Educación puxo en marcha o Programa Nacional de Educación Solidaria en 1997. Este programa difunde e pretende instaurar nas escolas a metodoloxía da aprendizaxe-servizo. Organiza múltiplas accións formativas entre as que destaca o Seminario Internacional Anual de Aprendizaxe-Servizo, edita publicacións e convoca os premios presidenciais Escuelas Solidarias e Prácticas Educativas Solidarias en Educación Superior. Tal foi o éxito da aprendizaxe-servizo no país austral que no 2007 a Lei de educación nacional incluíu explicitamente a proposta da aprendizaxe-servizo (art. 32 gr. e 123.1).

A partir do modelo arxentino, no ano 2008 o Ministerio de Educación de Ecuador crea o programa de Escolas Solidarias, e tamén o Premio Presidencial de Escolas Solidarias. Entre os anos 2008-2010, 103717 nenas e nenos ecuatorianos participaron en proxectos de aprendizaxe-servizo ${ }^{38}$.

Sen marchar de Arxentina temos que destacar o traballo realizado polo Centro Latinoamericano de Aprendizaxe e Servizo Solidario (CLAYSS) ${ }^{39}$, que ten como misión "contribuír ao crecemento dunha cultura fraterna e participativa en América Latina a través do desenvolvemento de proxectos educativos solidarios". Esta institución pretende ser unha rede, un punto de encontro para centos de entidades que practican a aprendizaxe-servizo, así como servir de apoio para aquelas que están a comezar a súa andadura neste ámbito.

Outra entidade arxentina que goza de gran prestixio e que foi de especial importancia no desenvolvemento do aprendizaxe-servizo no país é a Fundación SES ${ }^{40}$, acrónimo que responde aos tres valores da institución: sustentabilidade, educación e solidariedade.

Tamén no país veciño, Chile, se desenvolveron avances neste sentido. No ano 2001 a Corporación Participa e a Fundación Avina puxeron en marcha o programa Universidade: constrúe pais ${ }^{41}$, en que se implicaron once universidades chilenas, co propósito de expandir o concepto e a práctica da responsabilidade social no sistema universitario. No ano 2007 o Ministerio de Educación difundiu un documento en que se relacionan os con-

\footnotetext{
${ }^{37}$ N. H. Cecchi, "Aprendizaje-servicio en educación superior. La experiencia latinoamericana. Presentación Seminario Internacional Responsabilidad Social Universitaria: Aprendizaje Servicio - Caracas - Abril 2006", Universidad Central de Venezuela (sen data de publicación [01/02/2016]): dispoñible en http://www.ucv.ve/ uploads/media/AS_en_ES_Nestor_Horacio_Cecchi.pdf.

${ }^{38}$ Ochoa, "Aprendizaje-servicio en América Latina", 108-125.

${ }^{39}$ CLAYSS, "Misión, objetivos y líneas de trabajo", CLAYSS (sen data de publicación [01/02/2016]): dispoñible en www.clayss.org.ar/01_quienes/mision.htm.

${ }^{40}$ Fundación SES, "Quiénes somos", Fundación SES (sen data de publicación [01/02/2016]): dispoñible en www. fundses.org.ar/somos.html.

${ }^{41}$ Fernández et al., eds., Responsabilidad social universitaria. Una manera de ser universidad. Teoría y práctica en la experiencia chilena (Santiago de Chile: Funny).
} 
tidos establecidos pola Lei de educación para a educación media e a metodoloxía da aprendizaxe-servizo ${ }^{42}$.

O Centro de Voluntariado de Uruguai é, así mesmo, unha institución que debe terse en conta na difusión da aprendizaxe-servizo no seu país. Ao respecto, no ano 2007 preséntase o programa Aprendendo xuntos, en que se sentan as bases para transformar os programas de voluntariado en proxectos de aprendizaxe-servizo. Emulando o caso arxentino, creouse o Premio á Educación Solidaria, en colaboración co Goberno uruguaio, ademais de se editaren múltiplas guías e documentos en favor do traballo baseado nesta filosofía.

En Costa Rica, Venezuela e a República Dominicana o servizo estudantil callou de igual maneira con forza, e, de feito, estableceuse como requisito obrigatorio na educación de grao medio. Algunhas entidades aproveitan esta práctica obrigatoria para desenvolver proxectos de aprendizaxe-servizo. Nos casos costarriqueño (1975) e venezolano (2005), os estudantes universitarios teñen que realizar traballos de servizo á comunidade como requisito para graduarse.

Debemos salientar, con todo, o caso de México, pioneiro no servizo estudantil universitario en América Latina, xa que desde 1910 (desde a Revolución mexicana)- a propia Constitución inclúe o servizo social como unha obriga para os universitarios. Desde logo, déronse así múltiplas modalidades de experiencias de servizo comunitario, e como tales algunhas eran, claramente, de aprendizaxe-servizo aínda que non se recoñeceron como tales. Arestora, a aprendizaxe-servizo é perfectamente coñecida e hai exemplos que constitúen unha referencia mundial no desenvolvemento e investigación da metodoloxía. Sería de xeito destacado o caso do Instituto Tecnolóxico de Monterrey, que recentemente incorporou a aprendizaxe-servizo como unha metodoloxía didáctica para utilizar nas actividades académicas ${ }^{43}$.

Ollados os exemplos anteriores, pode que América Latina sexa bo modelo de prácticas de aprendizaxe-servizo, dada a experiencia que se foi acumulando naquelas latitudes. 0 percorrido non foi parello nas súas demarcacións nacionais, pero foron bastantes os países que optaron pola aprendizaxe-servizo como unha metodoloxía de interese pedagóxico para os distintos niveis dos sistemas educativos. En México, Costa Rica, Colombia e Perú acadou unha forza importante nas universidades, mentres que na Arxentina, Chile, Brasil, Bolivia e a República Dominicana o seu desenvolvemento foi maior nas escolas de ensino medio.

\section{A aprendizaxe-servizo en Europa e en España}

Europa tamén se viu influída pola chegada da aprendizaxe-servizo, aínda que de xeito máis tardío que nos Estados Unidos ou en América Latina. Así, en 2003 créase a European Service-Learning Asociation (ESLA), en cuxa primeira reunión participan represen-

\footnotetext{
${ }^{42}$ D. Eroles, Aprendizaje-servicio en el currículum escolar de enseñanza media en Chile (Santiago de Chile: Ministerio de Educación del Gobierno de Chile, 2007).

${ }^{43}$ E. Benavides e A. Barrera, Manual operativo de aprendizaje-servicio (Monterrey: Publicaciones de la Dirección de Formación Social del Tecnológico de Monterrey, 2007).
} 
tantes chegados de Alemaña, Holanda, Suecia, Noruega e España ${ }^{44}$. Un fito moi importante neste nivel foi o proxecto europeo de investigación CIVICUS, promovido pola Vytautas Magnus University de Lituania, no marco do cal se exploraron as formas de cooperación entre universidades, empresas, institucións, administración, organizacións...

Debemos salientar algunhas entidades europeas que traballan polo desenvolvemento e a implantación da aprendizaxe-servizo nos seus respectivos territorios. No caso alemán, financiada pola Fundación Freudenberg, creouse Lernen durch Engagement (LDE), que nace como unha rede nacional de escolas, centros de excelencia e entidades de cooperación para traballar en conxunto na difusión e o desenvolvemento da calidade da aprendizaxe a través do compromiso social. Esta entidade publicou unha ampla gama de materiais para a súa difusión, alén de organizar múltiplos encontros entre profesionais da educación co obxecto de fomentar o intercambio de experiencias. Cabe subliñarmos que a cultura alemá conta cunha longa tradición pedagóxica en que destacaremos ilustres pensadores como Johann Heinrich Pestalozzi, Paul Natorp e Georg Kerschensteiner, entre outros clásicos que avogaron por unha educación baseada na experiencia.

Se agora nos fixamos en Holanda, unha das principais entidades que difunden a aprendizaxe-servizo é o MOVISIE, instituto nacional para o coñecemento e consultoría, que achega consellos e solucións para facer fronte aos problemas sociais no campo da asistencia social, a participación e a seguridade social. No entanto, o desenvolvemento de iniciativas do tipo das que nos ocupan iniciouse cando o Goberno propuxo, en 2007, unha lei que tiña por finalidade implantar a aprendizaxe-servizo no currículo do ensino secundario. En 2011 establécese como algo obrigatorio, malia que, na práctica, a totalidade dos centros holandeses xa se implicaran no proxecto dun modo ou outro, con anterioridade. $\mathrm{Na}$ actualidade, un $97 \%$ das escolas holandesas participa, directa ou indirectamente, en proxectos de aprendizaxe-servizo, que atinxen $080 \%$ dos estudantes ${ }^{45}$.

Tamén se creou o Centro Suízo de Aprendizaxe-Servizo, que, ao igual que nos casos que vimos presentando, ten como finalidade o desenvolvemento e a implementación de proxectos de aprendizaxe-servizo, cunha ampla gama de iniciativas.

No Reino Unido as prácticas de aprendizaxe-servizo non se coñecen con tal denominación e englóbanse dentro do que se entende como "educación para a cidadanía", xa que a concepción de servizo en Inglaterra non é entendida de igual modo que nos Estados Unidos $^{46}$. Neste sentido, unha organización que tivo un papel especialmente relevante é o Community Service Volunteers (CSV), pois aínda que tradicionalmente se centrou no fomento do voluntariado clásico, a súa área educativa impulsa o que chamamos aprendizaxe-servizo.

\footnotetext{
${ }^{44}$ Os representantes españois formaban parte da Asociación Española de Voluntariado (AEVOL).

${ }^{45}$ L. García-Ajofrín, "El voluntariado "práctica obligatoria" en la Secundaria de los Países bajos", Boluntariotza.net (27/08/2010 [01/02/2016]): dispoñible en http://www.boluntariotza.net/es/noticia_boletin.asp?id=5130.

${ }^{46} \mathrm{~L}$. Jerome, "Service Learning and Citizenship Education in England", Education, Citizenship and Social Justice 7, 1 (2012): 59-70
} 
Temos constancia de que se desenvolveron tamén iniciativas neste sentido máis alá de Europa, en países asiáticos como Filipinas, India, Israel, Singapur ou o Xapón, e tamén en Australia ou en Suráfrica ${ }^{47}$, mais sen especial proxección ou repercusións no plano mundial ${ }^{48}$.

No Estado español, a aprendizaxe-servizo comeza a coñecerse a finais do século XX. Existen varias razóns para explicar esta tardía chegada:

1) A primeira é a falta de tradición neste tipo de enfoques educativos. Ademais, como é ben sabido, ata 0 ano 1975 vivimos nunha ditadura en que o asociacionismo estaba limitado e a educación cívica apenas existía como tal.

2) Estivo tamén motivada polos trazos curriculares, no sentido de que as metodoloxías eran fundamentalmente maxistrocéntricas e tradicionais, de xeito que asignaban escaso papel á iniciativa dos estudantes.

3) Unha terceira razón desta reducida influencia pode estar vinculada á ausencia desta modalidade formativa no espazo universitario.

4) Por outra parte, este tipo de iniciativas non encaixaba axeitadamente cos exiguos niveis de participación e compromiso social dunha incipiente sociedade civil en España.

Hai máis razóns de índole social, política ou cultural, pero as mencionadas poden servir para explicar o lento discorrer no noso estado da ApS, de que se empezan a facer eco algúns grupos de investigación na universidade e certos movementos de renovación pedagóxica en Valencia, Cataluña ou Madrid cando remata o século XX.

A partir de 2002 o Forum Cívico Educativo de Madrid márcase como obxectivo principal educar nenos, adolescentes e mozos en valores cívicos e éticos, en cidadanía e solidariedade, para fomentar a participación nos asuntos sociais e cívicos da súa comunidade; para promover, así mesmo o seu desenvolvemento persoal, social e académico a través de métodos como o service-learning ou a aprendizaxe e o servizo solidario. Deste xeito, comezan a organizarse seminarios de formación de profesorado, inícianse contactos institucionais coas administracións e procúrase establecer un marco de referencia da aprendizaxe-servizo en España ${ }^{49}$.

Case en paralelo, a Asociación Española de Voluntariado (AEVOL), con sede igualmente en Madrid, organiza a primeira conferencia sobre service-learning en abril de 2002. Desde ese momento, AEVOL comeza a desenvolver diferentes sesións de formación por

\footnotetext{
${ }^{47}$ H. A. Berry e L. A. Chrisholm, Service-Learning Higher Education around the World: An Initial Look (Nova York: Ford Fundation, 1999).

${ }^{48}$ A. Martínez-Odría, "Service-learning o aprendizaje-servicio: la apertura de la escuela a la comunidad local como propuesta de educación para la ciudadanía”, Bordón. Revista de pedagogía 59, 4 (2010): 627-640.

${ }^{49}$ Martínez-Odría, "Service-learning o aprendizaje-servicio".
} 
diferentes puntos do Estado. Esta mesma asociación foi promotora, en 2003, da primeira reunión da ESLA ${ }^{50}$.

Nestes anos, o Grup de Recerca en Educació Moral (GREM) da Universitat de Barcelona, xunto con outras institucións como a Fundació Catalá de l'Esplai ou a Fundació Jaume Boffill, entre outras, comeza a desenvolver iniciativas de aprendizaxe-servizo en diferentes lugares do seu ámbito e a exercer influencia sobre outros. Ademais, paralelamente leva a cabo un traballo de investigación relacionado con esta metodoloxía, o que 0 vai convertendo nun apreciable referente tanto español como internacional, con textos como os de: Martín e Rubio (2006) $)^{51}$, Puig et al. (2007) $)^{52}$, Martínez (2008) ${ }^{53}$, Puig et al. $(2009)^{54}$ e Batlle $(2013)^{55}$.

Compre salientarmos a creación nos últimos anos do Centre Promotor d'Aprenentatge Servei (CPAS) en Barcelona, impulsado por diferentes institucións e organismos cataláns como os que vimos de sinalar. Tal e como se recolle na súa páxina web ${ }^{56}$, o dito centro pretende ser "un espacio generador de iniciativas y confluencia de acciones encaminadas a facilitar y reforzar los proyectos de ApS. Es una entidad con voluntad de servicio público, independiente de la Administración, que trabaja para asociar el ApS a la innovación y a la calidad educativa".

O eixe central do CPAS é o seu espazo virtual (www.aprenentatgeservei.com), que serve como plataforma para achegar numerosos documentos, guías, experiencias..., ademais de ser a súa principal fonte de información cara ao exterior. Tamén cabe destacar 0 traballo realizado na organización de xornadas de intercambio de experiencias, xornadas de formación e a liña de axudas económicas que tratan de impulsar a aprendizaxe-servizo. Esta última iniciativa ten un peso moi importante en Cataluña para o desenvolvemento de novos proxectos de ApS, xa que serve de aliciente para implicar o maior número posible de persoas interesadas no desenvolvemento deste tipo de prácticas.

En Euskadi nace en 2009 a Fundación Zerbikas. A iniciativa partiu da Federación Sartu, a Fundación Vivir sen Drogas e a organización Edex. Na súa páxina web (www. zerbikas.es) defínense como "Centro Promotor del Aprendizaje y Servicio Solidario en Euskadi". É un espazo xerador de iniciativas, un lugar de confluencia de accións encamiñadas a facilitar e reforzar proxectos de aprendizaxe e servizo solidario. Tamén é unha

\footnotetext{
${ }^{50}$ A. Mencos, "Sociedad y voluntariado. Desarrollo de proyectos de Service-Learning para la preservación, conocimiento y difusión del patrimonio cultural español" VI Jornadas de Voluntariado Cultural, Pontevedra, 17 e 18 de xuño de 2003 (sen data de publicación [01/02/2016]): dispoñible en http://www.mcu.es/cooperacion/CE/ CongresosJornadas/voluntariado-cultural/ponencias.html.

${ }^{51}$ X. Martín e L. Rubio, Prácticas de ciudadanía. Diez experiencias de aprendizaje-servicio (Barcelona: Octaedro, 2006).

${ }^{52}$ Puig et al., Aprendizaje servicio. Educar para la ciudadanía.

${ }^{53}$ M. Martínez, Aprendizaje servicio y responsabilidad social de las universidades (Barcelona: Octaedro, 2008).

${ }^{54}$ Puig et al., Aprendizaje Servicio (ApS). Educación y compromiso cívico.

${ }^{55}$ R. Batlle, El aprendizaje-servicio en España: el contagio de una revolución pedagógica necesaria (Madrid: Editorial PPC, 2013).

${ }^{56}$ Ver www.aprendizajeservicio.net
} 
entidade con vontade de servizo público, independente da Administración, que asocia a aprendizaxe e o servizo solidario coa innovación e a calidade educativa, cuxa finalidade é "generar conocimiento en torno al aprendizaje y servicio solidario, así como promover, difundir y articular proyectos basados en esta metodología".

A expansión da ApS en España vai sendo un feito. Testemúñano, entre outros, o traballo de Roser Batlle e os seus datos acerca de como nas demais comunidades autónomas españolas se vai introducindo paulatinamente tal metodoloxía de traballo educativo. Esta pedagoga catalá vén sintetizando en diferentes informes anuais a situación da aprendizaxe-servizo en España e o xeito en que se foi propagando o dito enfoque nos diferentes territorios.

A finais de 2010 creouse en Portugalete (Bilbao) a Rede Española de AprendizaxeServizo (REDApS), como un lugar de encontro e colaboración entre institucións educativas, organizacións de acción social e profesionais que impulsan esta metodoloxía educativa en diversos ámbitos e comunidades autónomas ${ }^{57}$. A REDApS organiza un encontro anual a que acoden distintos profesionais, grupos e institucións con percorrido práctico. $O$ último destes encontros tivo lugar en Logroño en 2014, baixo os auspicios do Grupo Promotor de ApS da Rioxa. En definitiva, e como se explica na presentación que fai na súa páxina web (www.aprendizajeservicio.net), esta entidade é unha rede de redes heteroxénea, horizontal e lixeira, sen personalidade xurídica propia, inspirada nos valores que están na base da aprendizaxe-servizo: confianza, xenerosidade, cooperación e respecto.

Nace tamén no 2010 en Barcelona a Rede ApS (U), que serve como eixe vertebrador para as universidades españolas que practican e difunden a aprendizaxe-servizo. Este espazo de traballo serve para poñer en común estratexias, pautas e modelos de implantación usados polos diferentes profesionais da educación superior.

O interese polo tema fíxose presente tamén en Galicia, de modo asociado ao estudo e investigación do Grupo Esculca, da Universidade de Santiago de Compostela (USC). No seo deste grupo con sede na Facultade de Ciencias da Educación, que incorpora 0 enfoque como eixe de intervención pedagóxica nalgún dos seus proxectos de investigación, xa se deron á luz diferentes traballos de investigación sobre o tema, algúns traducidos e editados en libros e artigos en revistas especializadas. Así mesmo, a ApS veuse difundindo estes últimos anos na nosa comunidade autónoma grazas á súa presenza nos programas de formación permanente do profesorado de ensinanzas non universitarias, dunha parte; e, da outra, á súa incorporación dentro do programa de formación docente da USC nos seus dous campus de Compostela e Lugo. Cabe destacarmos, por fin, a recente creación da Asociación Galega de Aprendizaxe-Servizo, que integra colectivos e particulares de diferentes ámbitos educativos aos cales une 0 interese por esta metodoloxía.

\footnotetext{
${ }^{57}$ Ver www.aprendizajeservicio.net
} 


\section{Recapitulando}

A aprendizaxe-servizo chega a países da área anglosaxona europea e, posteriormente, a España, tras un longo percorrido de máis dun século nos Estados Unidos de América, onde a tradición deste tipo de enfoques é maior. Destacamos a grande influencia na definición e orientación da aprendizaxe-servizo do filósofo e pedagogo John Dewey, grazas ao seu enfoque centrado na aprendizaxe experiencial.

Desde unha perspectiva pedagóxica, o fomento da participación é un dos grandes retos aínda pendentes dunha efectiva realización. Temos que seguir avaliando as súas fortalezas nos planos educativo, social, cultural e económico, sen desmaiar en cantas experiencias positivas poidamos animar desde as diversas expresións educativas e a comunidade como un todo. No específico caso universitario, estamos ante unha magnífica oportunidade para fomentarmos a relación universidade-sociedade dun xeito permeable, tratando de contribuír a unha formación integral do alumnado, coa finalidade xeral de que vaia callando a educación da responsabilidade en cada un e unha dos educandos, suxeitos de dereitos e tamén de deberes canto ao seu perfil de cidadáns capaces de contribuír ao benestar e ao progreso da comunidade. 
